\title{
VON RECKLINGHAUSEN'S DISEASE
}

\author{
Khan S, Chandra A*, Jain N*, Kumar A*, Khan I U*
}

\section{ABSTRACT}

\begin{abstract}
Von Recklinghausen's disease (VRD) is a rare genetic autosomal dominant disorder that affects the ectodermal tissues (nerve and skin). The cardinal features of this disorder are spots of increase pigmentation (cafe-aulait spot, CAL), peripheral nerve tumours (neurofibromatosis) and iris hamartoma (Lisch nodule). Clinical diagnosis of VRD is based on the criteria given by National Institute of Health (NIH) because the mutation analysis is laborious. Here, we are reporting a case of a family with VRD.
\end{abstract}

\section{Key Words: VonRecklinghausen's disease (VRD), Cafe-au-lait (CAL) spot, Lisch nodule, Neurofibromatosis (NF)}

\section{INTRODUCTION}

Neurofibromatosis (NF) is an autosomal dominant disease ${ }^{1}$ It is characterized by disordered growth of ectodermal tissues (nerve \& skin) and is part of a group of disorders called Phakomatoses (neurocutaneous syndrome). NF is of two Types: NF-1 and NF-2. NF-1 is also called VRD. ${ }^{2}$ The gene which is responsible, is located on the long arm of chromosome 17q11.2. ${ }^{3}$ Its incidence is 1:3.000 births and present in about 30 persons per 10.000 populations. In a study, positive family history of NF1 was found in $71.2 \%$ and about $28.8 \%$ percent of cases arose as new mutations. ${ }^{1}$ Once the change has occurred the mutant gene can pass in the succeeding generations. ${ }^{4}$ The major disease features of this disorder are spots of increased skin pigmentation (CAL spots), peripheral nerve tumors (cutaneous neurofibromas) and iris hamartoma (Lisch nodule). It may be associated with a variety of others dysplastic abnormalities of the skin, nervous system, bones, endocrine organs and blood vessels. ${ }^{1}$

The diagnosis of NF1 is not difficult on being evident on clinical grounds. The diagnostic criteria are: A patient meeting two or more of the following criteria can be diagnosed as suffering from NF 1-(\) Neurofibromas - Two or more, or one plexiform neurofibroma (ii) CAL macules - Six or more measuring $1.5 \mathrm{~cm}$ in their greatest dimension (iii) - Freckling - In the axillary or inguinal areas (iv) Optic glioma (v) Iris hamartomas (Lisch nodules) - Two or more (vi) Sphenoid dysplasia or thinning of the cortex of the long bones (vii) Firstdegree relative .In difficult cases- biopsy of a neurofibroma can be diagnostic. Magnetic resonance and CT are important in the diagnosis of spinal nerve root tumors, intracranial tumors and hamartomas. ${ }^{2}$

Some workers have discovered gene responsible for NF1, which produces a protein known as neurofibromin. The gene is proposed to be a suppressor gene. Inactivation of neurofibromin leads to a disruption in cell growth regulation that may lead to tumor development. ${ }^{3}$ Basic studies in molecular genetics may lead one day to nonsurgical or pharmacologic treatments aimed at retarding or suppressing tumors associated with the neurofibromatoses. ${ }^{4}$

* Nepalgunj Teaching Hospital, Nepalgunj, Nepal.

Address for correspondence : Dr. Salamat Khan Nepalgunj Teaching Hospital NGMC, Banke, Nepal.

Email: drsalamatkhan63@yahoo.com 
CASE REPORT

A 45 years old lady admitted in the Department Of Surgery at Teaching Hospital, Kohalpur, NGMC, Banke, Nepal, with blunt injury of chest by bull. On examination, there were multiple neurofibromas on the face, chest, back and abdomen (Fig.1). On enquiring about the family history, she revealed that her two sons were having some problem in the skin. On Examination, the elder son who was 18 years old had plexiform neurofibromatosis of Vth nerve with pigmented patches all over the body (more than six) (Fig.2) while, the youngest son, aged about 8 years, had brown discoloration on the buttock and of abdomen with other smaller spots of brown pigmentation on the trunk (Fig.3).

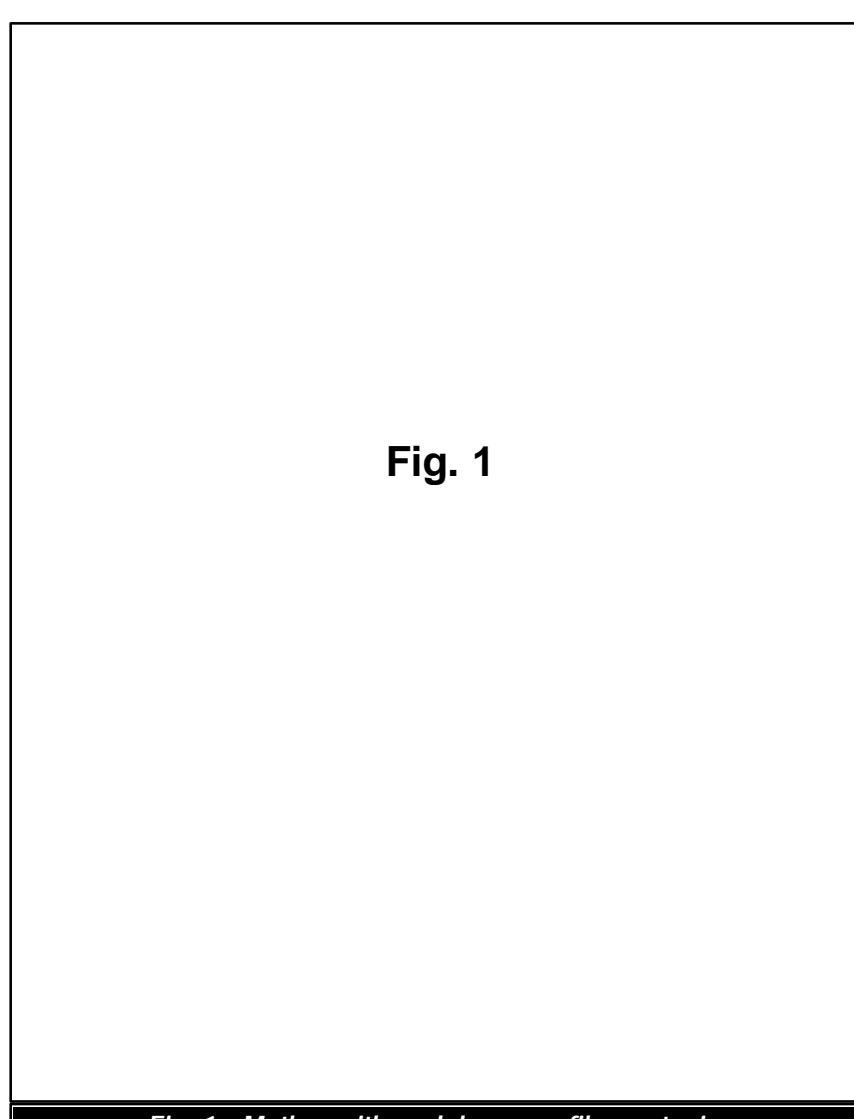

Fig. 1 : Mother with nodular neurofibromatosis.

\section{DISCUSSION}

The diagnosis of von Recklinghausen's disease (NF1) is made on the basis of the NIH criteria. These patients fulfill the required two criteria for the diagnosis viz (i) they are firstdegree relatives (mother and her two sons) (ii) three members of the same family are involved, i.e. mother had nodular fibromatosis with more than six CAL spots, her elder son had plexiform neurofibromatosis of fifth nerve and CAL spots and the youngest son had big nevus on the buttock. ${ }^{4}$ The treatment of the patient is dependent on age. In adult patients the aim' of treatment is only controlling the symptoms because most of the cases of NF1 are mild, live normal and productive life.

Fig. 2

Fig. 2 : Elder son of the family with plexiform neurofibromatosis and CAL

Fig. 3

Fig. 3 : Youngest son of the family with hyper pigmented patch on the buttock.

Surgery is advised in the cases that are having either bone malformations, painful disfiguring tumour or rarely when the tumour becomes malignant (3-5\%), however there is the chance of the tumour may grow back and in great numbers. Radiation 
and chemotherapy may be used as adjuvant to surgery. ${ }^{2}$ Regular follow-up of these patients are very important as they may develop nervous system, bones, endocrine and blood vessel abnormalities. Renal artery stenosis may lead to hypertension. In childhood the diagnosis is difficult Penetration of the gene is complete by the age five and diagnosis is made on regular follow -up, to the age of ten. Ophthalmologist, Dermatologist, Neurosurgeon and Pediatrician should examine these children annually. Visual Evoked Potentials/ MRI should be utilized for screening for the optic glioma in children under the age of 10 years. These patients should also be checked-up for the disturbance of puberty, delayed growth, psychomotor development and learning disabilities. Genetic counseling is important aspect of management and prenatal diagnosis is now potentially possible. It is essential that mildly affected adults can have a severely affected child, particularly the risk of mental retardation. Unfortunately there is no way of predicting which gene carriers will be severely affected. There is $50 \%$ risk of transferring NF1 to off-sprigs. ${ }^{2}$

\section{REFERENCE}

1. North KN : Neurofibromatosis 1 in childhood. Semin Pediatr Neurol 1998 Dec; $5(4)$ : 231-42.

2 The Phakomatoses. In Wynngaarden JB, Smith LH, Bennet JC (eds) : Cecil Textbook of Medicine, $20^{\text {th }}$ Edition. W B Saunders Company, 1996.

3. de Goede-Bolder A, Chossen MH, Dooijes D, vanden Ouweland AM, Niermeijer MF: Ned Tijdschar Genes; From gene to disease; nerofibromatosis type 12001 Sep 8; 145 (36) : 173638.

4. NF conference statement : National Institute of Health consensus development conference; Arch Neurol 1988; 45: 575-78.

5. MC Gaughran JM, HarrisDI, Donnai D, Teare D, MacLeod R, Westerbeek et al: Clinical study of type 1 neurofibromatosis in northwest England. Jmed Genet 1999 Mar; 36 (3) : 197-2037.

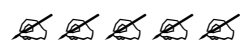

